\title{
Efeito da extração assistida por enzimas sobre a recuperação de compostos com propriedades antioxidantes de cascas de banana
}

\author{
Gabriel A. O. Scafi, Ruann J. S. de Castro.
}

\section{Resumo}

O objetivo do presente trabalho foi avaliar a recuperação de compostos bioativos da casca de banana nanica (Musa acuminata) por meio do uso isolado e combinado das enzimas pectinase (Pectinex XXL) $(0,5 \% \mathrm{v} / \mathrm{v})$ e celulase (Celluclast) $(0,5 \% \mathrm{v} / \mathrm{v})$ e avaliar as propriedades antioxidantes dos extratos obtidos. Os resultados demonstraram que 0 tratamento enzimático não teve impacto positivo sobre as propriedades antioxidantes dos extratos. O maior valor de atividade antioxidante para o método DPPH foi 33,34 $\mu \mathrm{moL}$ TE/g detectada no extrato obtido a partir da casca de banana liofilizada e não hidrolisada. Já para o método ABTS, o extrato obtido a partir das cascas de banana secas em estufa e não tratadas (controle) na concentração de $5 \mathrm{mg} / \mathrm{mL}$ atingiram atividade máxima de 151,23 $\mu \mathrm{moL} \mathrm{TE} / \mathrm{g}$.

\section{Palavras-chave: Cascas de banana, Compostos bioativos, Tratamentos enzimáticos}

\section{Introdução}

A utilização de resíduos agroindustriais para a recuperação de compostos bioativos por meio de tratamentos enzimáticos é uma alternativa consciente de gerenciamento de resíduos e subprodutos na indústria de alimentos. A casca de banana, por exemplo, é um resíduo produzido em larga escala, destacando-se por ser uma matriz rica em compostos com capacidade antioxidante. Nesse contexto, o objetivo do presente trabalho foi avaliar a recuperação de compostos com propriedades antioxidantes da casca de banana utilizando a extração assistida por enzimas.

\section{Resultados e Discussão}

Os resultados obtidos para propriedades antioxidantes em função da inibição de radicais DPPH e capacidade sequestradora do radical $\mathrm{ABTS}+$ em cada tratamento utilizando-se diferentes enzimas estão apresentados nas Tabelas 1 e 2, respectivamente.

Os dados de atividade antioxidante indicaram que o uso das enzimas não exerceu influência positiva na extração e recuperação dos compostos bioativos da casca de banana e na maior parte dos casos até reduziu esse potencial nos extratos produzidos. O pequeno efeito da ação das enzimas sobre a casca de banana pode ter uma relação direta com a alta solubilidade dos compostos fenólicos provenientes desta matriz, não sendo necessário um tratamento adicional para solubilizá-los no meio reacional.

A redução nas propriedades antioxidantes dos extratos, por sua vez, pode estar fortemente associada à oxidação de compostos fenólicos durante o processo de extração por ação das enzimas polifenoloxidase e peroxidase, presentes em grande quantidade em bananas.

Avaliando-se comparativamente as propriedades antioxidantes das amostras secas em estufa e liofilizadas, ficou evidenciado que a secagem em estufa permitiu a produção de extratos de casca de banana mais ricos em compostos antioxidantes.
Tabela 1. Inibição de radicais DPPH dos extratos obtidos após tratamento enzimático de casca de banana nanica seca em estufa e liofilizada.

\begin{tabular}{|c|c|c|c|c|c|c|c|}
\hline \multicolumn{8}{|c|}{ Inibição de radicais DPPH } \\
\hline \multirow[b]{2}{*}{ Tratamento } & \multirow{2}{*}{$\begin{array}{c}\text { Concentração } \\
(\mathrm{mg} / \mathrm{mL})\end{array}$} & \multicolumn{2}{|c|}{$\mu \mathrm{moL} \mathrm{TE} / \mathrm{g}$} & \multirow[b]{2}{*}{$\begin{array}{l}\text { Varração } \\
(\%)\end{array}$} & \multicolumn{2}{|c|}{$\mu \mathrm{moL} \mathrm{TE} / \mathrm{g}$} & \multirow[b]{2}{*}{$\begin{array}{l}\text { Variação } \\
(\%)\end{array}$} \\
\hline & & $\begin{array}{l}\text { Controle } \\
\text { (estufa) }\end{array}$ & $\begin{array}{l}\text { Hidrolisados } \\
\text { (estufa) }\end{array}$ & & $\begin{array}{c}\text { Controle } \\
\text { (liofilizado) }\end{array}$ & $\begin{array}{r}\text { Hidrolisados } \\
\text { (liofilizado) }\end{array}$ & \\
\hline \multirow{3}{*}{$\begin{array}{l}\text { Hidrólise com } \\
\text { celulase }\end{array}$} & 5,0 & $32,71 \pm 1,03$ & $33,02 \pm 0,07$ & 0,94 & $33,34 \pm 0,28$ & $21,85 \pm 1,97$ & $-34,46$ \\
\hline & 7,5 & $21,53 \pm 0,17$ & $21,62 \pm 0,17$ & 0,41 & $21,97 \pm 0,12$ & $21,02 \pm 0,07$ & $-4,32$ \\
\hline & 10,0 & $16,09 \pm 0,07$ & $16,11 \pm 0,36$ & 0,12 & $16,30 \pm 0,18$ & $16,56 \pm 0,04$ & 1,60 \\
\hline \multirow{3}{*}{$\begin{array}{l}\text { Hidrólise com } \\
\text { pectinase }\end{array}$} & 5,0 & $32,71 \pm 1,03$ & $33,01 \pm 0,32$ & 0,92 & $33,34 \pm 0,28$ & $21,83 \pm 1,73$ & $-34,52$ \\
\hline & 7,5 & $21,53 \pm 0,17$ & $21,86 \pm 0,31$ & 1,53 & $21,97 \pm 0,12$ & $21,00 \pm 0,55$ & $-4,41$ \\
\hline & 10,0 & $16,09 \pm 0,07$ & $16,42 \pm 0,30$ & 2,05 & $16,30 \pm 0,18$ & $16,65 \pm 0,08$ & 2,15 \\
\hline \multirow{3}{*}{$\begin{array}{l}\text { Hidrólise com } \\
\text { celulase e } \\
\text { pectinase }\end{array}$} & 5,0 & $32,71 \pm 1,03$ & $33,70 \pm 0,71$ & 3,03 & $33,34 \pm 0,28$ & $15,39 \pm 0,67$ & $-53,83$ \\
\hline & 7,5 & $21,53 \pm 0,17$ & $22,01 \pm 0,27$ & 2,23 & $21,97 \pm 0,12$ & $15,98 \pm 2,00$ & $-27,26$ \\
\hline & 10,0 & $16,09 \pm 0,07$ & $16,53 \pm 0,31$ & 2,73 & $16,30 \pm 0,18$ & $14,50 \pm 0,46$ & $-11,04$ \\
\hline
\end{tabular}

Tabela 2. Capacidade sequestradora do radical ABTS+ dos extratos obtidos após tratamento enzimático de casca de banana nanica seca em estufa e liofilizada.

\begin{tabular}{|c|c|c|c|c|c|c|c|}
\hline \multicolumn{8}{|c|}{ Capacidade sequestradora do radical ABTS+ } \\
\hline \multirow[b]{2}{*}{ Tratamentos } & \multirow[b]{2}{*}{$\begin{array}{c}\text { Concentração } \\
(\mathrm{mg} / \mathrm{mL})\end{array}$} & \multicolumn{2}{|c|}{$\mu \mathrm{moL} T \mathrm{TE} / \mathrm{g}$} & \multirow[b]{2}{*}{$\begin{array}{l}\text { Variação } \\
\text { (\%) }\end{array}$} & \multicolumn{2}{|c|}{$\mu \mathrm{moL} T \mathrm{TE} / \mathrm{g}$} & \multirow[b]{2}{*}{$\begin{array}{l}\text { Variaçã } \\
(\%)\end{array}$} \\
\hline & & $\begin{array}{l}\text { Controle } \\
\text { (estufa) }\end{array}$ & $\begin{array}{c}\text { Hidrolisado } \\
\text { (estufa) }\end{array}$ & & $\begin{array}{c}\text { Controle } \\
\text { (liofilizado) }\end{array}$ & $\begin{array}{r}\text { Hidrolisados } \\
\text { (liofilizado) }\end{array}$ & \\
\hline \multirow{3}{*}{$\begin{array}{l}\text { Hidrólise com } \\
\text { celuluse }\end{array}$} & 5,0 & $151,23 \pm 0,91$ & $149,32 \pm 8,71$ & $-1,26$ & $112,68 \pm 0,07$ & $111,14 \pm 9,74$ & $-2,99$ \\
\hline & 7.5 & $101,09 \pm 0,03$ & $100,70 \pm 0,12$ & $-0,38$ & $112,26 \pm 2,14$ & $79,18 \pm 0,71$ & $-29,46$ \\
\hline & 10,0 & $75,76 \pm 0,01$ & $75,65 \pm 0,02$ & $-0,14$ & $114,57 \pm 0,11$ & $67,27 \pm 3,46$ & $-40,30$ \\
\hline \multirow{3}{*}{$\begin{array}{l}\text { Hidrólise com } \\
\text { pectinase }\end{array}$} & 5,0 & $151,23 \pm 0,91$ & $147,56 \pm 6,56$ & $-2,43$ & $112,68 \pm 0,07$ & $108,53 \pm 7,44$ & $-5,27$ \\
\hline & 7,5 & $101,09 \pm 0,03$ & $100,65 \pm 0,20$ & $-0,44$ & $112,26 \pm 2,14$ & $81,17 \pm 2,45$ & $-27,69$ \\
\hline & 10,0 & $75,76 \pm 0,01$ & $75,61 \pm 0,09$ & $-0,19$ & $114,57 \pm 0,11$ & $48,05 \pm 0,25$ & $-57,36$ \\
\hline \multirow{3}{*}{$\begin{array}{l}\text { Hidrólise com } \\
\text { celulase e } \\
\text { pectinase }\end{array}$} & 5,0 & $151,23 \pm 0,91$ & $138,31 \pm 4,41$ & $-8,54$ & $112,68 \pm 0,07$ & $84,71 \pm 14,81$ & $-26,06$ \\
\hline & 7,5 & $101,09 \pm 0,03$ & $101,00 \pm 0,07$ & $-0,08$ & $112,26 \pm 2,14$ & $82,71 \pm 2,90$ & $-26,32$ \\
\hline & 10,6 & $5,76 \pm 0,01$ & $75,74 \pm 0,06$ & $-0,02$ & $4,57 \pm 0,11$ & $88,93 \pm 15,33$ & $-21,0$ \\
\hline
\end{tabular}

\section{Conclusões}

A partir dos resultados obtidos para as amostras de casca de banana nanica, concluiu-se que o uso das enzimas celulase, pectinase ou a combinação das mesmas para extração de compostos bioativos nas condições de ensaio realizadas não apresentou efeito positivo sobre as propriedades antioxidantes dos extratos produzidos. No entanto, foi possível observar que as cascas de banana são fontes naturais de compostos com alta atividade antioxidante.

Agradecimentos

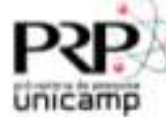

